УДК 004.421:004.65:378.147

DOI

Тетяна ВАКАЛЮК,

orcid.org/0000-0001-6825-4697

доктор педагогічних наук, дочент,

професор кафедри інженерії програмного забезпечення

Державного університету «Житомирська політехніка»

(Житомир, Україна) tetianavakaliuk@gmail.com

Ольга КОРОТУН,

orcid.org/0000-0003-2240-7891

кандидат педагогічних наук,

доиент кафедри комп'ютерних наук

Державного університету «Житомирська політехніка»

(Житомир, Україна) korotun-о@ztu.edu.иа

Інна СУГОНЯК,

orcid.org/0000-0002-0484-4839

кандидат технічних наук, дочент,

завідувач кафедри комп'ютерних наук

Державного університету «Житомирська політехніка»

(Житомир, Украӥна) isugonyak@gmail.com

Галина МАРЧУК,

orcid.org/0000-0003-2954-1057

старший викладач кафедри комп'ютерних наук

Державного університету «Житомирська політехніка»

(Житомир, Украӥна) mgv.555.mgv@gmail.com

\title{
ВИКОРИСТАННЯ ХМАРО ОРІЄНТОВАНОГО СЕРЕДОВИЩА В НАВЧАННІ БАЗ ДАНИХ МАЙБУТНІХ ФАХІВЦІВ ІЗ КОМП'ЮТЕРНИХ НАУК: РЕЗУЛЬТАТИ ПЕДАГОГІЧНОГО ЕКСПЕРИМЕНТУ
}

У статті представлено результати педагогічного експерименту щзодо впровадження методики використання хмаро орієнтованого середовищза в навчанні баз даних майбутніх фахівців із комп 'ютерних наук.

Під час проведення педагогічного експерименту для викладачів ЗВО проведено навчальні семінари «Змімане навчання як сучасна форма організаиії освітнього процесу у ЗВО», "Використання хмаро орієнтовано середовища у навчанні майбутніх фахівціів з комп ютерних наук», майстер-клас «Хмаро орієнтована система дистаниійного навчання Canvas».

Основна мета педагогічного експерименту - обтрунтування та об'єктивна перевірка ефективності розробленої методики як засобу підвищення рівня сформованості професійної компетентності майбутніх фахівців із комп'ютерних наук щзодо використання ХОС у навчанні БД. Під час проведення педагогічного експерименту сформовані КГ та ЕГ, проведені констатувальний зріз у КГ та ЕГ з метою визначення рівня сформованості зазначеної компетентності студентів щуодо використання ХОС у навчанні БД й кінцевий зріз у КГ та ЕГ щзодо визначення рівня професійної компетентності студентів, а також проаналізовано, опрацювано та узагальнено отримані результати експериментальної роботи.

Отже, якщо на початку формувального етапу експерименту за результатами констатувального зрізу розподіл студентів у КГ та ЕГ стосовно рівнів сформованості професійної компетентності студентів шодо використання ХОС у навчанні БД збігаються з рівнем значущяості 0,05, то вже в кінці експерименту за результатами кінцевого зрізу продемонстрована достовірність відмінностей характеристик КГ та ЕГ на рівні значущості менше за 0,01.

Результати проведеного педагогічного експерименту доводять, щчо застосування методики використання ХОС у навчанні БД призводить до підвищення рівня сформованості професійної компетентності майбутніх фахівців із комп'ютерних наук щзодо використання ХОС у навчанні БД.

Ключові слова: майбутні фахівці з комп'ютерних наук, хмаро орієнтоване середовище, хмаро орієнтовані засоби, бази даних, педагогічний експеримент. 
Tetiana VAKALIUK,

orcid.org/0000-0001-6825-4697

Doctor of Pedagogical Sciences, Associate Professor,

Professor at the Department of Software Engineering

Zhytomyr Polytechnic State University

(Zhytomyr, Ukraine) tetianavakaliuk@gmail.com

\author{
Olha KOROTUN, \\ orcid.org/0000-0003-2240-7891 \\ PhD in Pedagogics,
}

Associate Professor at the Department of Computer Science

Zhytomyr Polytechnic State University

(Zhytomyr,Ukraine) korotun-o@ztu.edu.ua

Inna SUGONYAK,

orcid.org/0000-0002-0484-4839

PhD of Technic Sciences, Assistant Professor,

Head of Computer Science Department

Zhytomyr Polytechnic State University

(Zhytomyr,Ukraine)isugonyak@gmail.com

Galyna MARCHUK,

orcid.org/0000-0003-2954-1057

Senior Lecturer Department of Software Engineering

Zhytomyr Polytechnic State University

(Zhytomyr, Ukraine)mgv.555.mgv@gmail.com

\title{
THE USE OF CLOUD-ORIENTED ENVIRONMENTS \\ IN THE LEARNING OF DATABASES OF FUTURE COMPUTER SCIENCE PROFESSIONALS: RESULTS OF A PEDAGOGICAL EXPERIMENT
}

The article presents the results of a pedagogical experiment on the implementation of a cloud-oriented environment in the learning of databases (COELDB) of future computer science professionals.

During the pedagogical experiment for teachers of institutions of higher education were held training seminars "Blended learning as a modern form of organization of educational process", "Using a cloud-oriented environment in the education of future computer science professionals", master class "Cloud-oriented system of Distance Learning Canvas".

The main purpose of the pedagogical experiment is to substantiate and objectively test the effectiveness of the developed methodology as a means of increasing the level of professional competence of future computer science specialists in the use of COELDB. During the pedagogical experiment, control and experimental groups were formed, the ascending section in the control and experimental groups were conducted in order to determine the level of formation of the specified competence of students in the use of COELDB and the final section in the control and experimental groups to determine the level of professional competence of students, and analysis was made, processing and summarizing the results of experimental work.

Thus, if at the beginning of the forming stage of the experiment, according to the results of the ascending section, the distribution of students in control and experimental groups with respect to the levels of students' professional competence in the use of COELDB training coincides with the significance level of 0.05 , then by the end of the experiment, by the results of the final section, control and experimental groups characteristics at a significance level of less than 0.01 .

The results of the pedagogical experiment prove that the application of the method of using COELDB training leads to an increase in the level of professional competence of future computer scientists in the use of COELDB.

Key words: future computer science professionals, cloud oriented environment, cloud oriented tools, databases, pedagogical experiment.

Постановка проблеми. Нині відбувається активне впровадження новітніх інформаційних технологій у всіх сферах суспільства, зокрема в освіті. У Законі України «Про освіту» зазначено: «Освіта $є$ головним державним пріоритетом, що забезпечує інноваційний, соціально-економічний і національно-культурний розвиток суспільства»
[2]. Як наслідок, в умовах сучасного інформаційного суспільства підвищується роль галузі вищої освіти в підготовці кваліфікованих кадрів.

Тому актуальним $є$ впровадження експериментальної методики використання хмаро орієнтованого середовища (далі - ХОС) у навчанні баз даних (далі - БД) майбутніх фахівців 
3 комп'ютерних наук у закладах вищої освіти (далі - 3ВО).

Аналіз досліджень. Теоретичною основою дослідження $є$ теоретичні аспекти застосування IКТ в навчанні М. І. Жалдака, М. Ю. Кадемія, В. В. Лапінського, Н. В. Морзе, Л. Ф. Панченко, С. О. Семерікова, О. М. Спіріна й інших.

Використання та проектування хмаро орієнтованого середовища представлено в дослідженнях В. Ю. Бикова, Т. А. Вакалюк, О. В. Коротун, С. Г. Литвинової, М. В. Рассовицької, А. М. Стрюка, М. П. Шишкіної та інших.

Мета статті - висвітлення педагогічного експерименту щодо результатів впровадження методики використання ХОС у навчанні БД майбутніх фахівців із комп'ютерних наук.

Виклад основного матеріалу. До педагогічного експерименту 3 використання ХОС у навчанні БД залучені студенти першого (бакалаврського) рівня вищої освіти.

Під час проведення педагогічного екперименту для викладачів 3ВО проведені навчальні семінари «Змішане навчання як сучасна форма організації освітнього процесу у ЗВО», «Використання хмаро орієнтовано середовища у навчанні майбутніх фахівців 3 комп'ютерних наук», майстер-клас «Хмаро орієнтована система дистанційного навчання Canvas».

Основна мета педагогічного експерименту обгрунтування й об'єктивна перевірка ефективності розробленої методики як засобу підвищення рівня сформованості професійної компетентності майбутніх фахівців 3 комп'ютерних наук щодо використання ХОС у навчанні БД. Під час проведення педагогічного експерименту сформовані КГ та ЕГ, проведені констатувальний зріз у КГ та ЕГ з метою визначення рівня сформованості зазначеної компетентності студентів щодо використання ХОС у навчанні БД та кінцевий зріз у КГ та ЕГ щодо визначення рівня професійної компетентності студентів, а також проаналізовано, опрацьовано й узагальнено отримані результати експериментальної роботи.

Перевірка ефективності впровадження авторської методики використання ХОС у навчанні БД майбутніх фахівців із комп'ютерних наук здійснювалася 3 урахуванням порівняльного методу наукового дослідження, сутністьь якого полягає в зіставленні в процесі дослідницької роботи результатів контрольних та експериментальних груп. Порівняємо та проаналізуємо дані констатувального й кінцевого зрізів цих груп про рівні сформованості професійної компетентності майбутніх фахівців з комп'ютерних наук щодо використання ХОС у навчанні БД.
Для підтвердження значущості визначених критеріїв і показників оцінювання рівня сформованості професійної компетентності майбутніх фахівців із комп'ютерних наук застосували метод експертного оцінювання.

На першому етапі педагогічного експерименту сформовані контрольні та експериментальні групи: до складу КГ увійшли майбутні фахівці 3 комп'ютерних наук, які вивчали дисципліну «Бази даних» за традиційною методикою (без використання ХОС); до складу ЕГ увійшли майбутні фахівці з комп'ютерних наук тих самих груп, що й до складу КГ, які вивчали БД за авторською методикою (з використанням ХОС).

Розподіл майбутніх фахівців із комп'ютерних наук на КГ та ЕГ відбувався на основі оцінок раніше вивчених суміжних дисциплін, а саме: «Основи програмування», «Основи об’єктноорієнтованого програмування».

Під час проведення педагогічного експерименту обов'язковою $є$ перевірка на рівнозначність вибірок майбутніх фахівців із комп'ютерних наук в КГ та ЕГ. У педагогічних дослідженнях доцільно використовувати непараметричні критерії статистики, тому для цього скористалися критерієм узгодженості Колмогорова - Смирнова ( $\lambda$-критерій Колмогорова - Смирнова).

Експериментальні дані повністю задовольняють обмеженням критерію Колмогорова - Смирнова: вибірки $\epsilon$ досить великими $\mathrm{n}_{\text {кг }}=76, \mathrm{n}_{\mathrm{er}}=75$; рівні знань упорядковані за спаданням; кількість рівнів більше ніж 3.

Сформулюємо статистичні гіпотези:

$\mathrm{H}_{0}$ : Вибірки (КГ та ЕГ) не відрізняються за рівнем знань із дисциплін «Основи програмування», «Основи об'єктно-орієнтованого програмування».

$\mathrm{H}_{1}$ : Вибірки (КГ та ЕГ) суттєво відрізняються за рівнем знань із дисциплін «Основи програмування», «Основи об’єктно-орієнтованого програмування».

Представимо таблицю для розрахунку критерію під час зіставлення рівнів знань в КГ та ЕГ (таблиця 1).

Максимальна різниця $\left(d_{\max }\right)$ між накопиченими емпіричними частками становить 0,02. Підрахуємо емпіричне значення критерію Колмогорова Смирнова $\left(\lambda_{\text {eмn }}\right)$ за формулою:

$$
\begin{gathered}
\lambda_{\text {eмn }}=d_{\max } \cdot \sqrt{\frac{n_{\kappa 2} \cdot n_{e 2}}{n_{\kappa 2}+n_{e z}}} \quad \lambda_{\text {enn }}=d_{\text {max }} \cdot \sqrt{\frac{n_{\kappa 2} \cdot n_{e 2}}{n_{\kappa 2}+n_{e z}}} \\
\lambda_{\text {enn }}=0,02 \cdot \sqrt{\frac{76 \cdot 75}{76+75}}=0,12 .
\end{gathered}
$$


Вакалюк T, Коротун О, Сугоняк I, Марчук Г. Використання хмаро орієнтованого середовиша..

За критичне значення критерію Колмогорова - Смирнова обрано $1,36\left(\lambda_{\mathrm{kp}}^{*}=1,36\right)$, тоді $\lambda_{\text {eиn }}<\lambda_{\kappa p}$. Отже, за статистичним критерієм Колмогорова - Смирнова, $є$ підстави стверджувати про відсутність відмінностей між вибірками. Тому приймається нульова гіпотеза, у якій зазначено, що майбутні вчителі інформатики у КГ та ЕГ за результатами навчання дисциплін «Основи програмування» й «Основи об'єктно-орієнтованого програмування» не відрізняються між собою за рівнем знань.

На другому етапі педагогічного експерименту для з'ясування рівня сформованості професійної компетентності майбутніх фахівців із комп'ютерних наук щодо використання ХОС у навчанні БД виконувався констатувальний зріз в експериментальних і контрольних групах (таблиця 2). Кожний критерій професійної компетентності студентів розглядався окремо й обчислювався за шкалою оцінювання, описаною вище.

Аналіз констатувального зрізу показав недостатність знань студентів із використання ХОС у навчанні баз даних. Як результат - низький i середній рівні сформованості критеріїв професійної компетентності майбутніх фахівців із комп'ютерних наук, а відповідно, низький і середній рівні сформованості ППК щодо використання ХОС у навчанні БД.

Спираючись на дані таблиці 3, здійснили перевірку достовірності гіпотези дослідження про відсутність зі статистичного погляду відмінностей між рівнями сформованості професійної компетентності студентів КГ та ЕГ за результатами констатувального зрізу. Застосували критерій $\varphi^{*}$ (кутове перетворення Фішера), призначений для зіставлення даних двох статистичних вибірок (КГ та ЕГ) за часткою, $з$ якою зустрічається ефект. Таким ефектом у дослідженні $є$ дотримання високого й достатнього рівнів сформованості професійної компетентності майбутніх фахівців із комп'ютерних наук щодо використання ХОС у навчанні БД. Застосування цього критерію дасть змогу оцінити достовірність розбіжностей між відсотковими частками наших двох вибірок, у яких зареєстрований ефект.

Статистичні гіпотези сформулювали так.

Нульова гіпотеза $\left(\mathrm{H}_{0}\right)$ : Частка майбутніх фахівців із комп'ютерних наук в ЕГ, у яких, за результатами дослідження рівнів сформованості професійної компетентності щодо використання ХОС у навчанні БД, спостерігається високий і достатній рівень, не більша, ніж у КГ.

Альтернативна гіпотеза $\left(\mathrm{H}_{1}\right)$ : Частка майбутніх фахівців із комп'ютерних наук в ЕГ, у яких, за результатами дослідження рівнів сформованості професійної компетентності щодо використання ХОС у навчанні БД, спостерігається високий і достатній рівень, більша, ніж у КГ.

Фактична таблиця емпіричних частот за двома значеннями описаної вище ознаки показала: якщо рівні сформованості професійної компетентності майбутніх фахівців із комп'ютерних наук щодо використання ХОС у навчанні БД визначені на високому та достатньому рівнях, то «є ефект», у протилежному випадку - «немає ефекту» (таблиця 3).

Таблиця 1

Таблиця для розрахунків за критерісм Колмогорова - Смирнова

\begin{tabular}{|c|c|c|c|c|c|c|c|}
\hline \multirow{2}{*}{ Рівень знань } & \multicolumn{2}{|c|}{$\begin{array}{c}\text { Емпіричні } \\
\text { частоти }\end{array}$} & \multicolumn{2}{c|}{$\begin{array}{c}\text { Емпіричні } \\
\text { частки }\end{array}$} & \multicolumn{2}{c|}{$\begin{array}{c}\text { Накочені емпіричні } \\
\text { частки }\end{array}$} & \multirow{2}{*}{ Різниця d } \\
\cline { 2 - 7 } & $\boldsymbol{K} \boldsymbol{\Gamma}$ & $\boldsymbol{E} \boldsymbol{\Gamma}$ & $\boldsymbol{K} \boldsymbol{\Gamma}$ & $\boldsymbol{E} \boldsymbol{\Gamma}$ & $\boldsymbol{K} \boldsymbol{\Gamma}$ & \\
\hline Високий & 10 & 11 & 0,13 & 0,15 & 0,13 & 0,15 & 0,02 \\
\hline Достатній & 33 & 32 & 0,43 & 0,43 & 0,56 & 0,58 & 0,02 \\
\hline Середній & 24 & 22 & 0,32 & 0,29 & 0,88 & 0,87 & 0,01 \\
\hline Низький & - & 10 & 0,12 & 0,13 & 1,00 & 1,00 & 0,00 \\
\hline
\end{tabular}

Таблиця 2

Розподіл студентів у КГ та ЕГ за рівнями сформованості критеріїв професійної компетентності щодо використання ХОС у навчанні БД

\begin{tabular}{|c|c|c|c|c|c|c|c|c|}
\hline \multirow{2}{*}{\begin{tabular}{|ll} 
Назва критерію & Рівень \\
\end{tabular}} & \multicolumn{2}{|c|}{ Високий } & \multicolumn{2}{|c|}{ Достатній } & \multicolumn{2}{|c|}{ Середній } & \multicolumn{2}{|c|}{ Низький } \\
\hline & КГ & EГ & КГ & $\mathbf{E \Gamma}$ & КГ & $\mathbf{E \Gamma}$ & КГ & $\mathbf{E \Gamma}$ \\
\hline Мотиваційний & 6 & 6 & 27 & 27 & 32 & 33 & 11 & 9 \\
\hline Організаційний & 8 & 5 & 13 & 16 & 43 & 37 & 12 & 17 \\
\hline Діяльнісний & 6 & 9 & 31 & 24 & 21 & 21 & 11 & 14 \\
\hline Когнітивний & 5 & 4 & 27 & 26 & 35 & 32 & 9 & 13 \\
\hline Навчальної взаємодії & 6 & 6 & 24 & 22 & 35 & 39 & 11 & 8 \\
\hline
\end{tabular}


В обрахунках використовувалися лише частки, що відповідають спостереженням, для яких $\epsilon$ ефект. Застосування критерію Фішера* можливе тому, що отримані експериментальні дані повністю задовольняють необхідним обмеженням цього критерію: жодна з часток, які порівнюються, не дорівнює нулю; кількість спостережень у двох вибірках більша ніж 5, що дає змогу робити будь-які зіставлення.

Таблиця 3

Таблиця для розрахунків за критерісм Фішера* під час порівняння КГ та ЕГ на початку педагогічного експерименту

\begin{tabular}{|c|c|c|c|c|c|}
\hline \multirow[b]{2}{*}{ Групи } & \multicolumn{2}{|c|}{ С ефект } & \multicolumn{2}{|c|}{ Немас ефекту } & \multirow[b]{2}{*}{ Усього } \\
\hline & 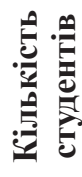 & $\begin{array}{c}\frac{\pi}{5} \\
\frac{\pi}{5} \\
0^{\circ}\end{array}$ & 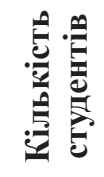 & $\begin{array}{l}\frac{\pi}{2} \\
\frac{5}{5} \\
\frac{5}{5} \\
\partial^{\circ}\end{array}$ & \\
\hline КГ & 30 & $39,5 \%$ & 46 & $60,5 \%$ & 76 \\
\hline $\mathrm{E} \Gamma$ & 32 & $42,7 \%$ & 43 & $57,3 \%$ & 75 \\
\hline
\end{tabular}

У дослідженні емпіричне значення менше за критичне $\left(\varphi_{\mathrm{em}}^{*}<\varphi_{\mathrm{kp}}^{*} ; 0,39<1,64\right)$, отже, робимо висновок про незначимість розходжень. Вибірки однакові, справедливою є нульова гіпотеза. Тобто 3 рівнем значущості 0,05 частка майбутніх фахівців із комп'ютерних наук в ЕГ, у яких, за результатами дослідження, високий і достатній рівні сформованості професійної компетентності щодо БД, не більша, ніж у КГ. Отже, групи студентів КГ та ЕГ однорідно підібрані за складом і на початку експерименту не відрізнялися за рівнем сформованості професійної компетентності щодо використання ХОС у навчанні БД.

Метою третього етапу педагогічного експерименту стало проведення кінцевого зрізу для перевірки ефективності розробленої методики як засобу підвищення рівня сформованості професійної компетентності майбутніх фахівців iз комп'ютерних наук щодо використання ХОС у навчанні БД. Кінцевий зріз проводив викладач, спостерігаючи за роботою студентів на лекції, під час виконання практичних вправ і лабораторних робіт, проектів тощо. Розподіл рівнів сформованості професійної компетентності майбутніх фахівців із комп'ютерних наук щодо використання ХОС у навчанні БД у КГ та ЕГ за результатами констатувального й кінцевого зрізів подано в таблиці 4.

Таблиця 4

Розподіл студентів у КГ та ЕГ за рівнями сформованості професійної компетентності за результатами констатувального й кінцевого зрізів

\begin{tabular}{|c|c|c|c|c|}
\hline \multirow[t]{2}{*}{ Рівень } & \multicolumn{2}{|c|}{$\begin{array}{c}\text { Констатувальний } \\
\text { зріз } \\
\text { (кількість студентів) }\end{array}$} & \multicolumn{2}{|c|}{$\begin{array}{c}\text { Кінцевий зріз } \\
\text { (кількість } \\
\text { студентів) }\end{array}$} \\
\hline & $\mathbf{K \Gamma}$ & $\mathbf{E} \boldsymbol{T}$ & $\mathbf{K \Gamma}$ & $\mathbf{E \Gamma}$ \\
\hline Низький & 10 & 11 & 8 & 5 \\
\hline Середній & 36 & 32 & 34 & 26 \\
\hline Достатній & 23 & 25 & 26 & 31 \\
\hline Високий & 7 & 7 & 8 & 13 \\
\hline Усього & 76 & 75 & 76 & 75 \\
\hline
\end{tabular}

Діаграма порівняльного розподілу студентів у КГ та ЕГ за рівнями сформованості професійної компетентності щодо використання ХОС у навчанні БД, за результатами констатувального й кінцевого зрізів, представлена на рис. 1.

Здійснимо перевірку достовірності гіпотези дослідження, а саме: наявність зі статистичного погляду відмінностей між рівнями сформованості професійної компетентності майбутніх фахівців

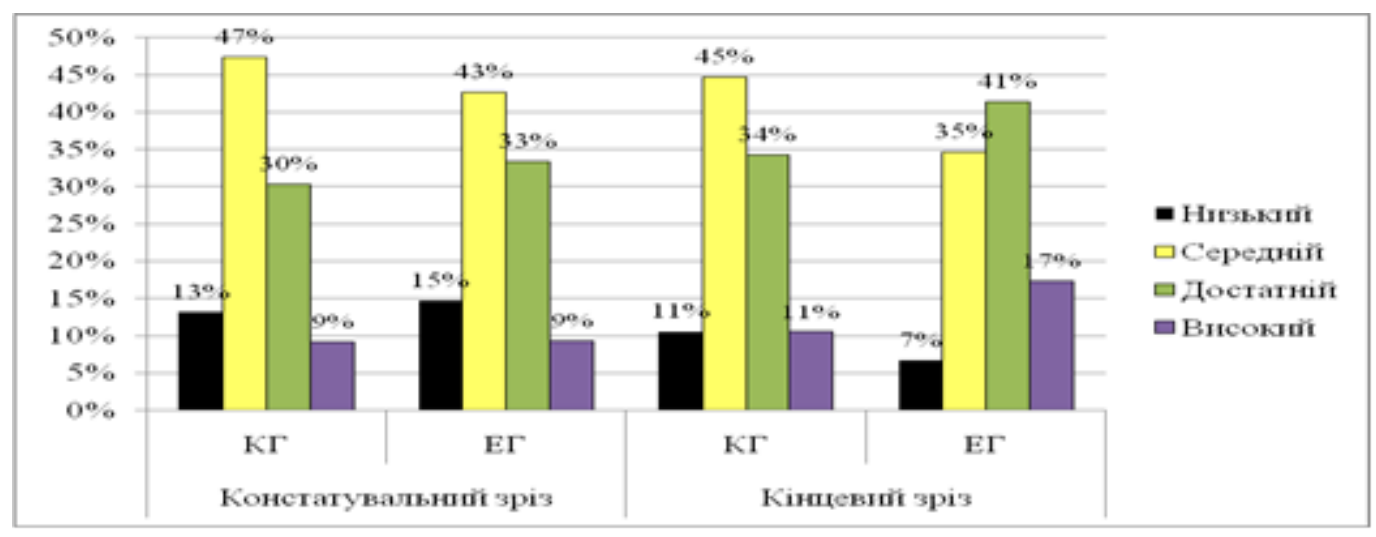

Рис. 1. Діаграма порівняльного розподілу студентів у КГ та ЕГ за рівнями сформованості професійної компетентності щодо використання ХОС у навчанні БД за результатами констатувального й кінцевого зрізів 
iз комп'ютерних наук щодо використання ХОС у навчанні БД у КГ та ЕГ за результатами кінцевих зрізів. Для цього застосуємо критерій Фішера*.

Сформулюємо статистичні гіпотези:

$\mathrm{H}_{0}$ : Частка майбутніх фахівців із комп'ютерних наук в ЕГ, у яких, за результатами дослідження, високий і достатній рівні сформованості професійної компетентності щодо використання ХОС у навчанні БД, не більша, ніж у КГ.

$\mathrm{H}_{1}$ : Частка майбутніх фахівців із комп'ютерних наук в ЕГ, у яких, за результатами дослідження, високий і достатній рівні сформованості професійної компетентності щодо використання ХОС у навчанні БД, більша, ніж у КГ.

Побудуємо фактичну таблицю емпіричних частот за двома значеннями ознаки: якщо рівні сформованості професійної компетентності майбутніх фахівців із комп'ютерних наук щодо використання ХОС у навчанні БД визначені на високому та достатньому рівнях, то «є ефект», інакше «немає ефекту» (таблиця 5).

Таблиця 5

Таблиця для розрахунків за критерісм Фішера* під час порівняння КГ та ЕГ наприкінці педагогічного експерименту

\begin{tabular}{|c|c|c|c|c|c|}
\hline \multirow[b]{2}{*}{ Групи } & \multicolumn{2}{|c|}{ С ефект } & \multicolumn{2}{|c|}{ Немас ефекту } & \multirow[b]{2}{*}{$\begin{array}{c}\text { Усього } \\
\text { студентів }\end{array}$} \\
\hline & 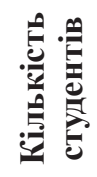 & $\begin{array}{l}\frac{\pi}{2} \\
\frac{\pi}{5} \\
\frac{\pi}{5} \\
\partial^{\circ}\end{array}$ & 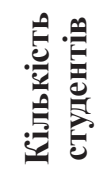 & $\begin{array}{l}\frac{\pi}{2} \\
\frac{\pi}{5} \\
\frac{\sigma}{5} \\
0^{\circ}\end{array}$ & \\
\hline КГ & 34 & $44,7 \%$ & 42 & $55,3 \%$ & 76 \\
\hline $\mathrm{E} \Gamma$ & 49 & $65,3 \%$ & 26 & $34,7 \%$ & 75 \\
\hline
\end{tabular}

Нагадаємо, що в розрахунках використовуються лише частки, що відповідають спостереженням, для яких $\epsilon$ ефект. Застосування критерію
Фішера* можливе тому, що експериментальні дані повністю задовольняють обмеженням: жодна 3 часток, що порівнюються, не дорівнює нулю; кількість спостережень у двох вибірках більша за 5 , що дає змогу робити будь-які зіставлення.

Після виконання необхідних дій отримали емпіричне значення $\varphi^{*}: \varphi_{\text {емп }}^{*}=2,56$. За критичне значення критерію Фішера* обрано 1,64 $\left(\varphi_{\mathrm{kp}}^{*}=1,64\right)$. Отже, отримали $\varphi_{\mathrm{eмr}}^{*}>\varphi_{\mathrm{kp}}^{*}$, емпіричне значення критерію Фішера* перебуває в зоні значущості, що свідчить про значні розбіжності у двох вибірках. Відповідно до термінів статистичних гіпотез: $\mathrm{H}_{0}$ відкидається, приймається $\mathrm{H}_{1}$. Тому за ступенем однорідності ознаки «рівні сформованості професійної компетентності майбутніх фахівців із комп'ютерних наук щодо використання ХОС у навчанні БД» є розбіжність між двома зазначеними вибірками. Достовірність відмінностей характеристик КГ та ЕГ за статистичним критерієм Фішера* на рівні значущості менша за 0,01 .

Висновки. Отже, якщо на початку формувального етапу експерименту за результатами констатувального зрізу розподіл студентів у КГ та ЕГ стосовно рівнів сформованості професійної компетентності студентів щодо використання ХОС у навчанні БД збігаються 3 рівнем значущості 0,05 , то вже в кінці експерименту, за результатами кінцевого зрізу, продемонстрована достовірність відмінностей характеристик КГ та ЕГ на рівні значущості менше за 0,01 .

Результати проведеного педагогічного експерименту доводять, що застосування методики використання ХОС у навчанні БД призводить до підвищення рівня сформованості професійної компетентності майбутніх фахівців із комп'ютерних наук щодо використання ХОС у навчанні БД.

\section{СПИСОК ВИКОРИСТАНИХ ДЖЕРЕЛ}

1. Азгальдов Г. Г., Райхман Э. П. Экспертные методы в оценке качества товаров. Москва : Экономика, 1974.152 с.

2. Про освіту : Закон України від 5 вересня 2017 року № 2145-VIII / Верховна Рада України. URL: http://www.zakon.rada.gov.ua/laws/show/2145-19.

3. Смирнов А. В., Смирнова Р. А. Статистическая обработка анкет, содержащих бальные шкалы. Резервы интенсификации учебно-воспитательного процесса педвуза : межвуз. сборник. науч. тр. Кострома, 1990. С. $117-121$.

4. Черепанов В. С. Основы педагогической экспертизы : учебное пособие. Ижевск : Изд-во ИжГТУ, 2006.124 с.

\section{REFERENCES}

1. Azgaldov G. G., Rayhman E. P. Ekspertnyie metodyi v otsenke kachestva tovarov. [Expert methods in assessing the quality of goods] Moscow: Economics, 1974. 152 p. [in Russian].

2. Zakon Ukrainy «Pro osvitu» [The Law of Ukraine «On Education»]: Law of Ukraine of September 05, 2017 No. 2145-VIII / The Verkhovna Rada of Ukraine. URL: http://www.zakon.rada.gov.ua/laws/show/2145-19 [in Ukrainian].

3. Smirnov A. V., Smirnova R. A. Statisticheskaya obrabotka anket, soderzhaschih balnyie shkalyi [Statistical processing of questionnaires containing point scales] Reserves of intensification of the educational process of the high school: internship. compilation. scientific tr. Kostroma, 1990. pp. 117-121 [in Russian].

4. Cherepanov V. S. Osnovyi pedagogicheskoy ekspertizyi [Fundamentals of pedagogical examination]: tutorial. Izhevsk: Publishing house IzhSTU, 2006. 124 p. [in Russian]. 